\title{
BIM in facilities management applications: A case study of a large university complex
}

Purpose: Building Information Modelling (BIM) in Facilities Management (FM) applications is an emerging area of research based on the theoretical proposition that BIM information, generated and captured during the lifecycle of a facility, can improve building operation. Using this proposition as a starting point, this research aims to investigate the value of BIM and the challenges affecting its adoption in FM applications.

Design/methodology/approach: Two inter-related research methods are utilised. The literature is utilised to identify the application areas, value and challenges of BIM in FM. Due to the lack of case studies identified in the literature review, and to provide empirical evidence of the value and challenges of BIM in FM, a case study of Northumbria University's city campus, is used to empirically explore the value and challenges of BIM in FM.

Findings: The results demonstrated that the value of BIM in FM stems from improvement to current manual processes of information handover; improvement to the accuracy of FM data, improvement to the accessibility of FM data and efficiency increase in work order execution. The main challenges were the lack of methodologies that demonstrate the tangible benefits of BIM in FM, the limited knowledge of implementation requirement including BIM for FM modelling requirements, the interoperability between BIM and FM technologies, the presence of disparate operational systems managing the same building and finally, the shortage of BIM skills in the FM industry.

Originality/value: There is lack of real-life cases on BIM in FM especially for existing assets, despite new constructions representing only $1-2 \%$ of the total building stock in a typical year. The originality of this paper stems from both adding a real life case study of BIM in FM in existing estate and providing empirical evidence of both the value and challenges of BIM in FM applications.

\section{INTRODUCTION}

Facilities management (FM) is an umbrella term under which a wide range of property and user related functions are brought together for the benefit of the organisation and its employees as a whole (Spedding and Holmes 1994). FM is holistic in nature, covering everything from real estate and financial management to maintenance and cleaning (Atkin and Brooks 2009). While researching and developing ways for the efficient management of facilities has been discussed since advent of the industrial revolution, the industry has seen this debate renewed with the emergence of BIM, and the proposition that BIM data captured during the project lifecycle can improve 
the efficiencies of facility management functions. BIM is defined as the process of generating, storing, managing, exchanging, and sharing building information in an interoperable and reusable way (Vanlande, Nicolle et al. 2008).

The operational phase of a building is the main contributor to the building lifecycle cost. Estimates show that the lifecycle cost is five to seven times higher than the initial investment costs (Lee, An et al. 2012) and three times the construction cost (BIM Task Group 2013). As a result, there is now a considerable economic and environmental need to manage both new and existing facilities in an efficient way. Governments around the world have recognised the inefficiencies affecting the construction industry in general, and have either recommended or mandated the use of Building Information Modelling (BIM) as a strategy to addressing a declining productivity. For example, the UK Government has mandated BIM level 2 - federated models held in separate discipline "BIM" tools with attached data - on all centrally procured projects from 2016, including the handover of digital data required for the operational phase (HM Government 2012). Although this mandate prescribes an operational handover specification there is still a limited amount of research on the FM industry with regards to BIM.

The applications of BIM for FM are much less explored compared to its implementation in planning, design and construction processes. In particular, efforts investigating BIM applications in FM have mainly focused on new buildings, despite new works making up only 1-2\% of the total building stock in a typical year (Kincaid 2004). There are also lack of real world cases on BIM applications in FM (Becerik-Gerber, Jazizadeh et al. 2011). In this paper, a contribution to this gap is added by investigating the value and challenges of BIM in FM using an extensive literature review and a real world case study. The case study was conducted on 32 non-residential buildings in Northumbria University’s city campus.

\section{LITERATURE REVIEW}

\subsection{Challenges of BIM in FM applications}

The lack of processes for updating the designed model with as built information is considered among the top challenges for BIM in FM applications (Gu and London 2010). Roles and responsibilities for providing the data and maintaining the model are not well defined (Becerik-Gerber et al., 2012).

Facility managers have traditionally been included in the building lifecycle in a very limited way and at the late phase of facility handover to clients (Azhar 2011). Additionally, design decisions are not usually challenged for their impact on operational cost or maintenance (British Institute of Facilities Management 2012). As a result of these challenges, BIM data for FM is either lacking or inadequate. "The FM field relies heavily on getting usable data from a BIM to do anything meaningful with it. All too often, this data is not really there or is inaccurate, as 
the model has not been updated with any design changes made after the design phase and is therefore not an accurate model of the facility as it is built" (Khemlani 2011).

The traditional procurement of FM contractors, in which FM contractors are appointed for a contracted period of time, generally 3-5 years, is also considered as an obstacle for BIM for FM applications. This change of contracts with FM contractors often entails notoriously poor handed-over data between the contractors, leading to additional survey costs being added to the fee. East and Brodt (2007) propose that current facility maintenance contractors are paid to survey the existing building to capture as-built conditions and the owner will have to pay over and over - once for the construction contractor to complete the documents at the end of construction - and again for the maintenance contractor survey and the start of every contract. This process is inherently ineffective as it leads to a duplication of information. It could be suggested that there needs to be improvement made to the workflow of handover data and the maintenance of that data through the life of the building.

The cultural approach to adopting new processes and technologies in the FM industry is also considered a key challenge. The FM industry is quite rigid in its approach to new technology, and unless BIM for FM benefits are clearly proven, its uptake in the FM industry will continue to be low (Becerik-Gerber, Jazizadeh et al. (2011). Indeed, there is a lack of demand by clients for BIM's for FM (Australian Institute of Architects 2010), which is exacerbated by a general lack of collaboration between project stakeholders for modelling and model utilisation (Becerik-Gerber et al., 2012). The lack of awareness by clients is exacerbated by a shortage of BIM skills and understanding by FM professionals (BIM Task Group 2013) and therefore, these two factors together are creating a vicious circle inhibiting BIM adoption in FM applications. Indeed, this is a very detrimental challenge as a BIM for FM uses requires continuous maintenance to remain valuable to the building itself and its owners (Becerik-Gerber et al., 2012).

Interoperability between BIM technologies and current FM technologies (e.g. CAFM - Computer Aided Facility Management Systems) is still an issue in the handover of information and data to operation stage (Akcamete, Liu et al. 2011). In existing assets, FM legacy systems are usually utilized for one or two decades and unless the transfer of BIM data to such legacy systems is aligned with or improves current modes of operation, and the value of BIM is demonstrated, it is unlikely that facility managers can prove the business cases for using BIM. Shen, Hao et al. (2012) do however, suggest that systems should be linked, and showcase a BIM system bolted on to a legacy facility management system. According to the (British Institute of Facilities Management 2012) there is a need for open systems and standardised data libraries that can be utilised by any CAFM or asset management system. Without such non-proprietary formats, facility owners and managers must enforce proprietary information systems or re-key information into a CAFM Systems. Owners and facility managers pay 
to have the data keyed into relevant FM systems (East and Brodt 2007). However, to date there is undefined fee structure for such an additional scope (Becerik-Gerber et al., 2012). There are also challenges based around updating the data, and where it is updated, whether it is in the native BIM or in the CAFM system (Lin and Su 2013).

An information exchange specification called COBie (Construction Operations Building Information Exchange) was developed to provide a structure for the lifecycle capture and delivery of information needed by facility managers (East and Nisbet 2010). While there is an agreement that COBie is necessary for structuring data (Open BIM Network 2012) and that structured data allows for greater interoperability (Hassanain, Froese et al. 2003), COBie "does not provide details on what information is to be provided, when and by whom" (East and Carrasquillo-Mangual, 2013, p.1). And there is still limited knowledge in the identification of such requirements. Only a brief summary of some non-geometric requirements was identified in recent studies (Becerik-Gerber et al., 2012). This challenge is best summarised by (Teicholz 2013) who argues that "Building information models delivered at project completion are a rich information source for FM, but not all of the information is valuable on a day to day basis within the broad range of an FM practice, where data retrieval, change management, and tracking costs and work activity are critical. Facility managers will need to detail and prioritise their information requirements". It is therefore suggested that a process for researching key information requirements need to be implemented within the industry.

The lack of contractual and legal framework for the implementation of BIM in general (Eastman, Teicholz et al. 2011), and for BIM for FM in particular (Becerik-Gerber et al., 2012), is a significant area of challenges. For the foreseeable future, legal and liability requirements in the building industry will dictate that contracts between the parties be conveyed in the traditional written and two-dimensional graphical form (Reddy 2011). The first legal risk to determine is ownership of the BIM data and how to protect it through copyright and other laws (Azhar 2011). Licensing agreements are emerging in BIM policies as a feasible option that allows limited use to another party while maintaining copyright and ultimate control (British Institute of Facilities Management 2012). However, this solution is challenged by the fact that there are difficulties with embedded data and model validation (Australian Institute of Architects 2010). As a result, most contract forms still require the handover of paper documents containing equipment lists, product data sheets, warranties, spare part lists, preventive maintenance schedules, and other information. This often leads to incomplete and inaccurate information that is difficult to access and utilise for the purpose of increasing FM efficiencies (Lin and Su 2013). 


\subsection{Value of BIM in FM applications}

Today most contracts require the handover of paper documents containing equipment lists, product data sheets, warranties, spare part lists, preventive maintenance schedules, etc. This information is essential to support the management of the facilities by the owner and facilities managers. The current process of information handover to FM phase is generally done manually. Information handed over is often incomplete and inaccurate (Lucas, Bulbul et al. 2013). The industry is spending millions of dollars, and thousands of man-hours recreating such information and working with inefficient workflows (Keady 2013). Of the $\$ 15.8$ billion loss caused by interoperability inefficiencies, $\$ 10.6$ billion are attributed to the owner and operator during the operations and maintenance phase of a building (Lee, An et al. 2012).

The improvement of handover processes is the among the main drivers for using BIM in FM (Gu, Singh et al. 2008). Despite current interoperability challenges, BIM data and information collected during the building lifecycle will reduce the cost and time required to collect and build FM systems (Teicholz 2013). For example, data regarding spaces, systems, finishes, etc. can be captured in digital format within a BIM and do not require to be re-created in downstream FM systems (Eastman, Teicholz et al. 2011). The ability to capture manufacturers information within 3D parametric objects reduces the need of duplicating asset information (Shen, Hao et al. 2012). BIM is considered as an enabler of improved data quality and reliability which will in turn result in increased workforce efficiencies (Teicholz, 2013). According to Eastman et al. (2011) the quality of data will improve as more people become accustomed to working in a BIM environment.

The ability of extracting and analysing views from BIM, specific to various needs and users, will provide information to make decisions and improve the delivery of facilities (Azhar 2011). For example, 3D visualisation can help FM technicians to better utilise their cognitive and perceptual reasoning for problem solving (Motamedi, Hammad et al. 2014). BIM visualisation provides accurate geometrical data that has never been possible before (CRC Construction Innovation, 2007) and can support the analysis of building proposals and the simulation and benchmark of performance (Atkin and Brooks 2009). For example, intelligent algorithms could be created to automate decision making for FM applications that has never been possible before the addition of digital data (Golabchi, Akula et al., 2013). Scenarios showing the benefits of BIM to FM interventions such as troubleshooting broken equipment and improving ergonomic and comfort conditions are described by Becerik-Gerber et al. (2012). Other important BIM in FM applications outlined literature are in space management, emergency management, energy control and monitoring, and personnel training and development (Jordani 2010, Li, Calis et al. 2012, Teicholz 2013, Dong, O'Neill et al. 2014, Motamedi, Hammad et al. 2014). 
There are also suggestions that adopting BIM in FM will facilitate the future involvement of facility managers at a much earlier design stage, in order to convey their input and influence on the design and construction of a building (Azhar 2011). The adoption of BIM in FM is also expected to provide ways for managing knowledge about building operation which can be utilised in future designs (BIM Task Group 2013).

For refurbishment projects, BIM and associated technologies such as laser scanning are expected to reduce the cost of producing as built information and the accuracy and reliability of FM information (Huber, Akinci et al. 2011). Researchers are already exploring ways for integrating the "scan to BIM" and the enhanced data capture of existing buildings with non-destructive testing techniques to analyse materials and existing properties, as these will not be captured in a scan (Volk, Stengel et al. 2014).

\section{METHODOLOGY}

The research question posed at the start of this paper was to investigate the value and challenges of BIM in FM for new and existing assets. The value of BIM in FM has been explored in the literature review. However, there is also a need to test this value and also explore further how BIM can add value to the FM of existing assets. A case study was collated and aimed to investigate the value of BIM in managing spaces selected as a specific FM function.

A case study typically combines a number of data collection techniques including archives, interviews, questionnaires, and observations (Eisenhardt 1989), and seeks to holistically explain and understand the dynamics of a contemporary phenomenon (Yin 2011). It is suggested that case studies are an ideal method when a holistic in-depth investigation is needed (Tellis 1997). Table 1 below shows in chronological order the adopted research.

Table 1 - Research path

\begin{tabular}{|l|l|}
\hline Literature Review & $\begin{array}{l}\text { Preliminary literature review } \\
\text { Identification of value and challenges }\end{array}$ \\
\hline Case Study & $\begin{array}{l}\text { Review archived FM documents and systems to create } \\
\text { an alternative BIM Specification } \\
\text { Evaluate and Conclude }\end{array}$
\end{tabular}




\section{CASE STUDY}

The case study was conducted on Northumbria University's city campus, which is based in Newcastle upon Tyne (UK). It is made up of 32 non-residential buildings with a gross area of over $120,000 \mathrm{~m}^{2}$. The case study started in 2010, when the University commissioned five developers to produce building information models with a focus on improving the performance of space management. The models were completed by the five developers in five weeks at a cost of approximately $£ 0.33 / \mathrm{m}^{2}$. Developers have used existing Estates Department's floor plans in DWG format, scans of the original elevations, sections in JPEG format, and space information in Excel databases. As the case study involves an existing asset, there are key challenges that the application of BIM for FM purposes has to consider. These are related to the strategic issues and the business case for migrating from the current FM processes to BIM-based FM processes. The case study involved personnel from the University's estates department who took part in detailed discussions investigating the value and challenges of BIM in managing the spaces of the existing university campus. The values and challenges explored are currently theoretical and will be used by the university in order to implement a robust and integrated BIM strategy. The results are summarised into the following categories.

\subsection{Workforce and process efficiencies}

The efficiency of processes associated with managing spaces, such as updating geometric and non-geometric information, came immediately to the fore when the functionalities of BIM for FM were explored in the BIM created for the campus. The University currently updates its drawings and information in two separate environments (i.e. floor plan drawings in two-dimensional graphical representation - i.e. DWG format - and a database in MS Excel format). Both require manual update, creating duplication of workload. Photographs and scanned elevations and sections from the original drawing sheets are used to verify specific details. With regular changes in building utilisation occurring year round, this is a lengthy task requiring the full time attention of a CAD technician. Using BIM for FM, the creation of geometric information and the inclusion of specific FM information allows automatic updating of required schedules; producing instant sections, elevations, three-dimensional visuals and renders, and generating drawing sheets from a single integrated environment (Figure 1 and 2). This provided efficiency gains that have not been possible to achieve with current processes and technologies utilised by the FM team. It was estimated that this will reduce the need for a full time CAD technician (salary approx. $£ 25,000$ per annum) and provide cumulative savings from improved efficiencies in future work orders over the years. Additional information relating to statutory compliance such as integrated asbestos register, emergency equipment, escape routes, accessibility and essential maintenance, can be easily traced, updated and reported in schedules. An example that includes an area of asbestos, properties of the asbestos type, its exact 
location, date of removal and location of survey documentation can be displayed in real time (Figure 3). Moreover, the estate department staff identified that BIM for FM models, with the augmentation of available BIM functionalities, can enhance key FM services such as room finding, fault-reporting, development and refurbishment option generation, and assessment of building performance. Such services lead to reduction in response times, with detailed campus knowledge assigned to specific buildings, levels, rooms, etc. For example, with each request to replace a light bulb on the campus, the maintenance staff could check in real time the bulb type and manufacturer using the FM model before carrying out the task. Another example could be to check the paint colour code for a room where the wall finish has been damaged, thus saving staff time and material resources. The developed BIMs for FM were used to trial option appraisal for redevelopment and refurbishment as phased plans, sections, elevations and 3D rendered views that could be quickly displayed and assessed (Figure 4). Such functionalities provide time and costs efficiency in future FM option appraisal and represent a platform for more accurate strategic decision making from a management perspective.

Insert Figure 1

Insert Figure 2

Insert Figure 3

Insert Figure 4

\subsection{Accuracy of records of geometric information}

The creation of a BIM have revealed that some areas of buildings on the campus failed to line up when the two dimensional drawings and elevation scans were used as a basis to build the models (figure 4). This has called upon the estate department to order new surveys to verify the building layout. It was also agreed that once the FM team achieve the required BIM skills, the maintenance of geometric records will be accomplished in a more efficient way from both economic and quality perspective.

Insert Figure 5

\subsection{Implementation challenge and maintenance of models}

Once the previously illustrated scenarios had demonstrated the value of BIM in FM, discussions with the FM estates department have shifted to understand the challenges associated with migrating from current FM processes to BIM based processes. Several implementation challenges were identified. There is a need to communicate and understand the benefits of BIM for FM with empirical examples such as the ones previously illustrated. The FM 
team must also have the skills to be in position of maintaining and controlling the BIMs for FM. A concise BIM for FM specification must be developed to define the information required to suit the particular requirements of the business and FM functions - space management in this specific case study.

It was also acknowledged that there are still industry-wide challenges related to technologies and processes. FM teams wishing to implement BIM for FM in the immediate future should be willing to adapt to such challenges. For example, one of the major concerns was the limited compatibility between BIM technologies and FM technologies (e.g. CAFM, building automation systems, building energy management, etc.) which can be exacerbated by the huge difference amongst the lifecycle of updates of BIM technologies, FM technologies and buildings. The lifecycle of updates of a BIM authoring platform is typically 12 - 24 months, with for example Autodesk Revit upgrading every year and older models not opening in new upgrades, whereas the lifecycle of FM legacy systems last much longer and building lifespan can be up to anything upwards of 50 years (Kincaid 2004). This means that data standards and interoperability will remain critical for the adoption of BIM for FM technologies in the mid and long term. Indeed, the authors' experience from several consultancy works conducted on BIM for FM projects, especially for existing assets, suggests that the FM data is stored in several disparate databases and is likely to be and methodologies that link BIM to these databases are needed. Therefore, FM organisations wishing to implement BIM for FM in the immediate term should take a long term view (e.g. minimum 5 years) and be willing to work with different standards and information formats. It was also identified that due to the evolving nature of the BIM for FM field, and the differences in the lifespans of technologies, FM organisations must not fit their FM business processes to suit a particular technology which would otherwise result in a continuous effort of adaptation. However, FM organisations can presently attain the benefits of BIM for FM through the development of a tailored BIM specification and templates (e.g. naming structure and standard to tie all existing systems together and to a BIM, information to be included, level of detail, object styles, line styles, units, export settings, etc.) that suit their particular business requirements. It has been found on live projects that in fact the geometry on FM models can be a lower level of development, so long as the data can be added or linked to the model. An example of the levels of development used in the case study is reported in Figure 7 using the AIA LODs (AIA, 2012). These AIA LODs have generally been set up with new buildings in mind where there is a need for a higher level of development during the construction process. Such specifications and templates will also help to engage with the supply chain on future work on the university campus and enable compatibility with the organisation's FM procedures.

Insert Figure 6 


\section{DISCUSSSION AND CONCLUSION}

BIM applications have been thoroughly discussed and researched at planning, design and construction phases. BIM in FM application is still considered an emerging field. The understanding of the challenges and value-adding potential of BIM in FM is fundamental at this early stage. To explore these areas, a literature review and confirmatory case study were used in this research. The findings provided evidence that there is agreement about the value and potential of BIM in FM. Such value stems mainly from:

- Improvement to the current manual processes of information handover; improvement to the accuracy of FM data;

- Increase of the efficiency of work orders execution, in terms of speed, to accessing data and locating interventions. Such value is derived from the capability of BIM to provide a data-rich visual and integrated data environment;

- Improvement in the accessibility of FM data that can be found within the model;

- Increase of efficiency for creating bespoke plans, elevations and visual renders all from the same model;

- The ability to attach legislative/statutory compliance data, which can be reported and scheduled out of the one model;

- The Potential for room finding and accurate fault reporting through the interrogation of the model; and

- The ability to scenario plan refurbishment projects in a $3 \mathrm{D}$ environment.

However, there are challenges that are hindering the exploitation of BIM in FM. The main challenges are:

- The lack of methodologies that demonstrate the tangible benefits of BIM in FM, which is reflected by limited demand for BIMs for FM by clients and operators;

- The need for rigorous BIM specifications for modelling requirements;

- The interoperability between BIM and FM technologies and the difference in their lifespan;

- Limited knowledge of requirements for the implementation of BIM in FM (e.g. what information is to be provided, when and by whom);

- The lack of open systems and standardised data libraries that can be utilised as a bridge between BIM and CAFM technologies;

- The current number of disparate operational systems, managing the same building;

- The lack of clear roles, responsibilities, contract and liability framework;

- The shortage of BIM skills in the FM industry; and

- The rigid industry cultural approach to adopting new processes and technologies. 
Another key finding was the lack of real-world case studies of BIM applications in FM. A real world case study of 32 non-residential buildings with a gross area of over 120,000 $\mathrm{m}^{2}$ was presented to provide empirical evidence of the value and challenges of BIM in FM and reveal new ones. The results from the case study demonstrated with practical examples how BIM can add benefits to the workforce, process efficiencies and to the accuracy of records of geometric information. In addition to the challenges identified in previous literature, discussion with estate department experts conducted during the case study revealed a further challenge which is inherent in the significant differences of life spans in BIM technologies, FM technologies and buildings. This means that FM organisations must be prepared to work with different information and data standards in the mid and long terms instead of adapting their business processes to fit a specific technology. The development of a BIM for FM specification that suits the need of the organisation's FM processes was identified as a key factor to exploit the benefit of BIM-based FM and enable organisations and their supply chain to work according to structured FM processes.

In summary it is believed that BIM for design and construction is better understood and the value for BIM and FM has yet to be demonstrated. A BIM for FM should meet the requirements of a building owner, meaning that clients need to understand and articulate their BIM requirements including the level of detail needed. The differing life span of technologies and buildings suggests that there is a requirement for open source standards that aid in maintaining the usability of models.

The results presented in this paper adds a contribution that can be used by researchers to develop methodologies of BIM for FM that understand and articulate appropriate client requirements, as this is paramount to the success of BIM and FM. Researchers and practitioners can use the identified challenges and values to develop studies that rank and address the critical success factors for the implementation of BIM in FM and ad-hoc strategies to achieve those factors.

\section{REFERENCES}

Akcamete, A., et al. (2011). Integration and visualization maintenance and repair work orders in BIM: lessons learned from a prototype. Proceedings of the 11th International Conference on Construction Applications of Virtual Reality (CONVR), , 3-4 November 2011, Weimar, Germany.

AIA (2012), "E203: Building Information Modelling and Data Exhibit”, The American Institute of Architects, Washington, DC, U.S.

Atkin, B. and A. Brooks (2009), “Total facilities management ( $3^{\text {rd }}$ Ed.)”, Chichester, UK: Wiley-Blackwell. 
Australian Institute of Architects (2010). BIM in Australia, Australian Institute of Architects, South Melbourne, Victoria, Australia.

Azhar, S. (2011). "Building Information Modeling (BIM): Trends, Benefits, Risks, and Challenges for the AEC Industry." Leadership and Management in Engineering, 11(3): 241-252.

Becerik-Gerber, B., et al. (2011). "Application areas and data requirements for BIM-enabled facilities management." Journal of construction engineering and management, 138(3): 431-442.

BIM Task Group (2013). Government Soft Landings: Departmental Implementation Brief, BIM Task Group.

British Institute of Facilities Management (2012) BIM and FM: Bridging the gap for success, Bishop's Stortford, Hertfordshire, UK.

Dong, B., et al. (2014). "A BIM-enabled information infrastructure for building energy Fault Detection and Diagnostics." Automation in Construction, 44: 197-211.

East, E. W. and N. Nisbet (2010). Analysis of life-cycle information exchange. Proceedings of the International Conference on Computing in Civil and Building Engineering, W. TIZANI (Editor).

East, W. and W. Brodt (2007). "BIM for construction handover." Journal of Building Information Modeling: $28-35$.

Eastman, C., et al. (2011). "BIM handbook: A guide to building information modeling for owners, managers, designers, engineers and contractors $\left(2^{\text {nd }} E d\right)$. ”, New Jersey, U.S.: Wiley.

Eisenhardt, K. M. (1989). "Building theories from case study research." Academy of management review 14(4): $532-550$.

Golabchi, A., et al. (2013). Leveraging BIM for Automated Fault Detection in Operational Buildings. 2013 Proceedings of the 30th ISARC, Montréal, Canada.

Gu, N. and K. London (2010). "Understanding and facilitating BIM adoption in the AEC industry." Automation in Construction 19(8): 988-999.

$\mathrm{Gu}$, N., et al. (2008). Adopting building information modeling (BIM) as collaboration platform in the design industry. CAADRIA 2008: Beyond Computer-Aided Design: Proceedings of the 13th Conference on Computer Aided Architectural Design Research in Asia, The Association for Computer Aided Architectural Design Research in Asia (CAADRIA).

Hassanain, M. A., et al. (2003). "Implementation of a distributed, model-based integrated asset management system." Journal of Information Technology in Construction 8: 119-134.

HM Government (2012). Building Information Modelling. Industrial strategy: government and industry in 
partnership. report URN 12/1327.

Huber, D., et al. (2011). Methods for automatically modeling and representing as-built building information models. Proceedings of the NSF CMMI Research Innovation Conference, January, 2011.

Jordani, D. (2010). "BIM and FM: The portal to lifecycle facility management." Journal of Building Information Modeling 6: 13-16.

Keady, R. A. (2013), "Financial Impact and analysis of equipment inventories", Facilities Engineering Journal, http://www.fmlink.com [accessed June 5th, 2013].

Khemlani, L. (2011). "BIM for Facilities Management." AEC Bytes, http://www.aecbytes.com [accessed June 5th, $2013]$.

Kincaid, D. (2004). "Adapting buildings for changing uses: guidelines for change of use refurbishment.", London and New York: Taylor \& Francis.

Lee, S.-K., et al. (2012). An Extension of the Technology Acceptance Model for BIM-based FM. Construction Research Congress 2012: Construction Challenges in a Flat World, ASCE.

Li, N., et al. (2012). "Measuring and monitoring occupancy with an RFID based system for demand-driven HVAC operations." Automation in Construction 24: 89-99.

Lin, Y.-C. and Y.-C. Su (2013). "Developing Mobile-and BIM-Based Integrated Visual Facility Maintenance Management System." The Scientific World Journal 2013.

Lucas, J., et al. (2013). "An object-oriented model to support healthcare facility information management." Automation in Construction, 31: 281-291.

Motamedi, A., et al. (2014). "Knowledge-assisted BIM-based visual analytics for failure root cause detection in facilities management." Automation in Construction 43: 73-83.

Open BIM Network (2012) Open BIM Focus - COBie, issue 4, Oct 2012.

Reddy, K. P. (2011). BIM for Building Owners and Developers: Making a Business Case for Using BIM on Projects, New Jersey, U.S.: John Wiley \& Sons.

Shen, W., et al. (2012). "A loosely coupled system integration approach for decision support in facility management and maintenance." Automation in Construction 25: 41-48.

Spedding, A. and R. Holmes (1994). "Facilities management." CIOB Book of Facilities Management, Harlow: Longman Scientific \& Technical.

Teicholz, P. (2013). BIM for Facility Managers, New Jersey, U.S.: John Wiley \& Sons.

Tellis, W. (1997). "Application of a case study methodology." The qualitative report 3(3): 1-17. 
Vanlande, R., et al. (2008). "IFC and building lifecycle management." Automation in Construction 18 (1): 70-78.

Volk, R., et al. (2014). "Building Information Modeling (BIM) for existing buildings-Literature review and future needs." Automation in Construction 38: 109-127.

Yin, R. K. (2011). Applications of case study research ( $3^{\text {rd }}$ Ed.), SAGE Publications, Inc. 